\title{
Anti-CD3/CD20 Bispecific Antibody GEN3013
}

National Cancer Institute

\section{Source}

National Cancer Institute. Anti-CD3/CD20 Bispecific Antibody GEN3013. NCI Thesaurus.

Code C163022.

\begin{abstract}
A bispecific monoclonal antibody, with potential immunomodulating and antineoplastic activities. Anti-CD20/CD3 monoclonal antibody GEN3013 contains two antigenrecognition sites: one for human CD3, a T-cell surface antigen, and one for human CD20, a tumor-associated antigen (TAA) that is exclusively expressed on B-cells during most stages of B-cell development and is often overexpressed in B-cell malignancies. Upon administration, GEN3013 binds to both T-cells and CD20-expressing B-lineage tumor cells. The resulting cross-linkage may trigger a potent cytotoxic T-lymphocyte (CT L) response against the CD20-expressing tumor B-cells.
\end{abstract}

